\title{
Shallow-Depth Slab Decarbonation as a control on the Deep Carbon Cycle
}

\author{
LEONIE ALENA STROBL ${ }^{1}$, OLIVER PLÜMPER ${ }^{2}$, \\ MARKUS OHL ${ }^{2}$ AND ANDREAS BEINLICH ${ }^{3}$ \\ ${ }^{1}$ Faculty of Geosciences \\ ${ }^{2}$ Utrecht University \\ ${ }^{3}$ University of Bergen \\ Presenting Author: 1.a.strobl@uu.nl
}

The mobilisation and transport of carbon within the lithosphere is a highly debated topic. Understanding the mechanism and quantities of carbon subducted into the mantle at trenches could provide significant insight into not only the petrological changes occurring with depth but also the influence of subduction on carbon-cycling. It has long been understood that the Earth's atmospheric carbon dioxide concentration and climate are intrinsically linked to tectonic plates as a major $\mathrm{CO}_{2}$ sink and as a control on the efficiency of mantle ingassing. The current understanding of carbonate stability with depth is controversial and while some models suggest that carbon-bearing phases are stable to sub-arc depths $[1,2]$ others suggest a shallow-depth carbon release [3]. The lack of available field observations that would allow for the quantification of subduction-related decarbonation and its driving force further enhances this disconnect. The observation of frozen-in decarbonation reaction textures at the $\mathrm{km}$ scale in previously carbonated, ultramafic, oceanic lithosphere in northern Norway [4] could provide important insight into shallow depth decarbonation processes. Field observations and textural analyses indicate breakdown of magnesium carbonate and serpentine to secondary olivine at depths shallower than $20 \mathrm{~km}$. A pseudomorphic replacement that likely was initiated and driven by changes in the $\mathrm{xCO}_{2}$ as a result of small-scale deformation generating a fluid pathway through the ultramafic lens. We present first field observations and reaction textures and will discuss possible implications of shallow-depth decarbonation on the efficiency of carbon transport into the Earth's mantle by subduction.

[1] Kerrick, D.M. \& Connolly, J.A.D. (1998). Geology 26, 375-378.

[2] Dasgupta, R. \& Hirschmann, M.M. (2010). EPSL 298, 113.

[3] Kelemen, P.B. \& Manning, C.E. (2015). PNAS 112, E3997-E4006.

[4] Beinlich, A., Plümper, O., Hövelmann, J., Austrheim, H. \& Jamtveit, B. (2012). Terra Nova 24, 446-455. 